\title{
Did Jesus Commit a Fallacy?
}

\section{DAVID HITCHCOCK McMaster University}

Key Words: Argument, fallacy, denying the antecedent.

Abstract: Jesus has been accused of committing a fallacy (of denying the antecedent) at John 8:47. Careful analysis of this text (1) reveals a hitherto unrecognized valid form of argument which can superficially look like the predicate-logic analogue of denying the antecedent; (2) shows that determining whether a published text can be fairly charged with committing a fallacy may require (but often does not get) extensive and detailed analysis; (3) acquits Jesus of the charge; and thereby (4) confirms a claim by Michael Burke that published arguments can seldom be fairly charged with denying the antecedent, or analogous fallacies.

Jesus said": "He that is of God heareth God's words: ye therefore hear them not, because ye are not of God." (John 8:47)

Rolf George claimed (1983: 323 ) that this argument has the (unique) form of denying the antecedent; since this form is invalid, George takes Jesus to be committing a fallacy. ${ }^{2}$ Michael Burke discusses the passage at some length (1994: 27-28) because it has an indicator word ("therefore") which signals that the initial conditional statement is part of the argument. In this respect John 8:47 differs from other real examples Burke found which are alleged to commit the fallacy of denying the antecedent: their wording leaves open that the conditional statement is not a premiss but a prefatory remark serving a rhetorical or dialectical function. Without an explicit indication that the conditional statement is a premiss, Burke argues, it is unfair to choose the less favourable interpretation and charge the authors of such texts with denying the antecedent.

As to John $8: 47$, Burke notes correctly that its initial statement is not a simple but a generalized conditional, so that the passage would if anything commit the predicate-logic analogue of denying the antecedent. (This is the fallacy of taking the following form to be valid: For every $x$, if $x$ is $G$, then $x$ is $H$. And $a$ is not G. So a is not $\mathrm{H}$.) Burke notes, again correctly, that John 8:47 is advanced as an explanation rather than an argument. (Jesus is speaking to a group of Jews who he claims do not believe him and intend to kill him. The quoted verse immediately follows Jesus' question: "If I speak truth, why do you not believe me?" This question clearly asks for an explanation rather than for evidence.) So Burke concludes that, if anything, the passage commits an error in the logic of explanation which is analogous to the predicate-logic analogue of denying the antecedent.

But does it in fact commit this error? Burke suggests that the King James translation used by George is a mistranslation. Burke cites four other translations, none of which (he claims) has an indicator word which requires the reader to take the conditional statement as offered in (explanatory) support of the fact that Jesus' audience does not hear (i.e. believe) him. 
Burke does not, however, look at the original Greek text, which reads as follows ${ }^{3}$ :

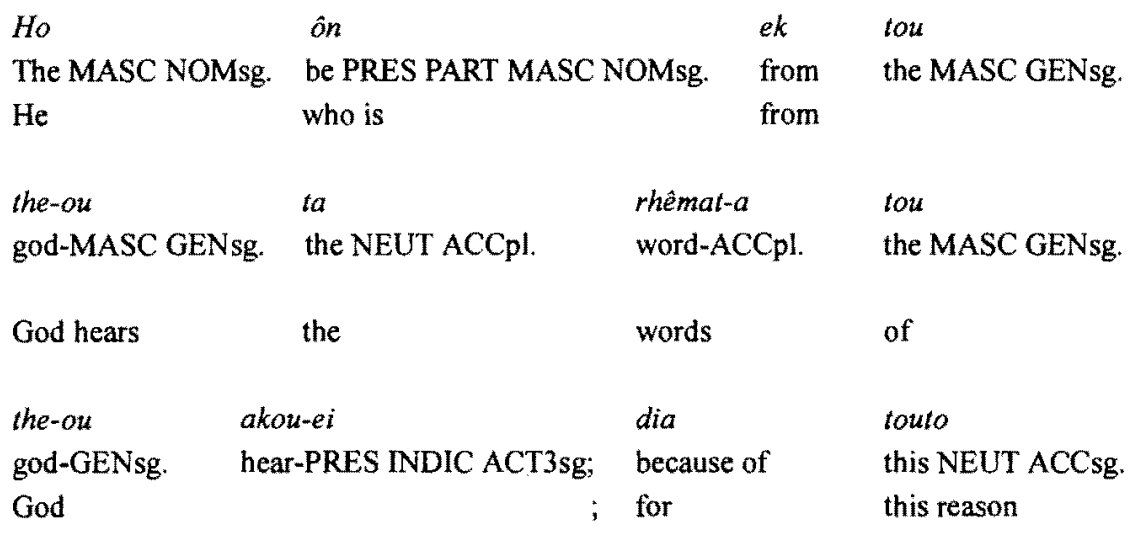

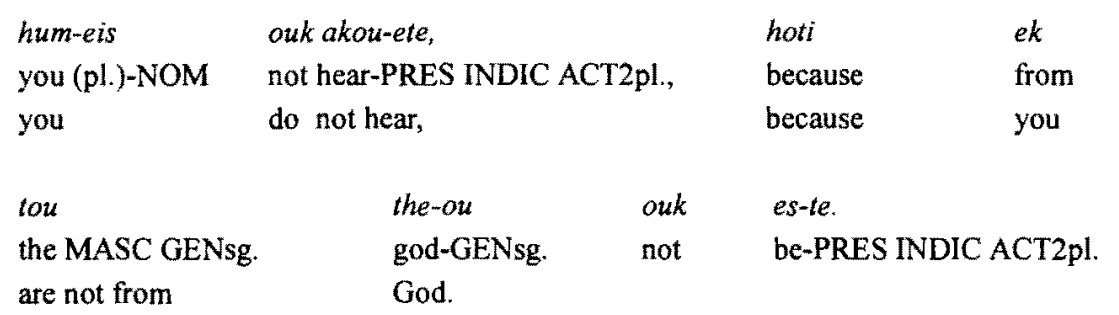

A crucial question in interpreting this passage is whether the word "this" (Greek "touto") refers backward to the generalized conditional preceding it or forward to the "because" clause which follows it. Greek has two words for "this". The word "hode" (neuter "tode") usually refers forward to a noun, noun phrase or clause immediately following it. "Touto" (masculine "houtos") often refers in the opposite direction to something immediately preceding; there are many examples in St. John's Gospel of such a backward-referring use of "touto", including uses in the phrase "dia touto". ${ }^{4}$ But "touto" can also be used in apposition to a substantive clause (Robertson 1919:698-700, Goodwin and Gulick 1930:216), in which case it generally precedes the clause to which it refers. We find five examples in St. John's Gospel $(5: 1,18 ; 10: 17 ; 12: 18,39)$ of such a forward reference of "touto" in "dia touto" to a "because" ("hoti") clause. Indeed, this is the usual pattern of reference where a sentence begins with "dia touto" ("for this reason") and ends with a "hoti" ("because") clause. Jesus is therefore saying: "You do not hear for this reason: because you are not from God."

Thus Burke is correct that there is no explicit indication that the preceding generalized conditional is part of Jesus' explanation why his audience does not believe him. But it must play some role in his arriving at this explanation, because it is sandwiched between Jesus' raising the question and his giving the 
answer. Its role, I suggest, is that of the premiss of an argument whose conclusion is the explanation:

Premiss: He who is from God hears the words of God.

Conclusion: You do not hear because you are not from God.

Note that the crucial claim in Jesus' conclusion is that his audience is not from God. ${ }^{6}$ It is already known to both him and his audience that they do not "hear" (i.e. believe) him. Given this background knowledge, Jesus is perfectly justified in inferring from his premiss that his audience is not from God; the core of his conclusion follows by the predicate-logic analogue of modus tollens: For every $\mathrm{x}$, if $x$ is $G$, then $x$ is $H$; $a$ is not $H$; therefore, $a$ is not $G$.

But, while Jesus is justified in inferring that his audience is not from God, is he justified in inferring that this fact is a reason why they do not believe him? Sliding over the subtleties of Jesus' argument, its basic form is: "Every G is $\mathrm{H}$. a is not $\mathrm{H}$. Therefore, $\mathrm{a}$ is not $\mathrm{H}$ because $\mathrm{a}$ is not G." Put so generally, the form is invalid. Consider the instance where we have "snowy day" for " $G$ ", "below freezing" for " $\mathrm{H}$ " and "today" for " $\mathrm{a}$ ": the premisses are true (every snowy day is below freezing, and we can suppose that today is not below freezing) but the conclusion is false (it is not true that today is not below freezing because today is not a snowy day). What has gone wrong in this case is that our sufficient condition $\mathrm{G}$ is not a causal sufficient condition for $\mathrm{H}$, but a sufficient evidential condition for it. The form of argument is valid, I maintain, for instances where $G$ is a sufficient causal condition for $\mathrm{H}$, and only for such instances. We can think of plausible examples:

(1) Every piece of uncoated silver tarnishes when exposed to air, and this does not tarnish when exposed to air, so this does not tarnish when exposed to air because it is not a piece of uncoated silver.

(2) Every person who is repeatedly betrayed by people whom they absolutely trust hates all human beings, and you do not hate all human beings, so you do not hate all human beings because you have not been repeatedly betrayed by people whom you absolutely trust.

The conclusion of such arguments must be understood as an explanation which supplies a causally necessary condition, rather than as one which supplies a causally sufficient condition. Further, an argument of this form does not justify a claim to exclusivity, to having established the one and only causally necessary condition for some state of affairs. Consider the following example, due to Robert W. Binkley:

(3) Being run over by a truck is a causally sufficient condition for being dead, and you are not dead, so you are not dead because you have not been run over by a truck.

The premisses are true of any reader of the argument (at the time of reading), and the conclusion (I would maintain) is also true. But of course there are many other causally necessary conditions of a particular person's not being dead: not having committed suicide, not having been infected with HIV before 1985, and so on. Similarly for other states of affairs. 
If being from God is a sufficient condition of hearing the words of God, it is natural to take it as a sufficient causal condition. Further, the claim that Jesus' hearers do not hear (i.e. believe) because they are not from God is not intended as an exclusive claim; Jesus has just finished saying (8:45) that they do not believe him because he speaks the truth. So Jesus' argument would be valid, since it is of a valid form. ${ }^{7}$ Thus Jesus does not commit a fallacy at John $8: 47 .^{8}$

What conclusions can we draw from the preceding analysis of this text? First, there is a valid form of argument, which can superficially look like the predicate-logic analogue of denying the antecedent, from a general causal claim of the form "Being $\mathrm{G}$ is a sufficient cause of being $\mathrm{H}$ " to a particular causal claim of the form "this is not $\mathrm{H}$ because it is not G". Second, determining whether a published text can be fairly charged with committing a fallacy can require extensive and detailed analysis. ${ }^{9}$ Third, at least in this instance, Jesus did nor commit a fallacy. And thus, fourth, we have additional confirmation of Michael Burke's claim that published arguments can seldom be fairly charged with denying the antecedent.

' King James translation. References here and elsewhere to what Jesus said and whether Jesus committed a fallacy should be understood as references to what Jesus is quoted as saying. I make no claim about what the historical Jesus actually said.

${ }^{2}$ George's reading of the text seems to have an early precedent. Richard Whately cites almost the same translation, in quotation marks but with no indication of its source or context, as example 12 in Appendix 2 of his Elements of Logic, first published in 1825 (cf. his 1827 , 326). He instructs the reader to reduce each example to syllogistic form or test it for validity by using logical rules. Read as it looks, the passage is an invalid argument with two premisses.

${ }^{3}$ Abbreviations: $2=$ second person, $3=$ third person, $\mathrm{ACC}=$ accusative, $\mathrm{ACT}=$ active, $\mathrm{GEN}=$ genitive, $\mathrm{INDIC}=$ indicative, $\mathrm{MASC}=$ masculine, $\mathrm{NEUT}=$ neuter, NOM $=$ nominative, PART = participle, $\mathrm{pl} .=$ plural, $\mathrm{PRES}=$ present, $\mathrm{sg} .=$ singular.

"Backward references of "touto" occurring after "dia": $6: 65,9: 23,12: 27,13: 11,16: 15,19: 11$. Backward references of "touto" not preceded by "dia": $5: 28 ; 6: 6,61 ; 7: 39 ; 8: 40 ; 11: 7,26$, $51 ; 12: 6,33 ; 13: 28 ; 18: 34,38 ; 19: 28 ; 20: 20,22 ; 21: 14,19$.

5 There are sentences beginning with "dia touto" and ending in a "hoti" clause where "hoti" means "that", e.g. John 6:65. But such sentences are not parallel to the text under consideration.

${ }^{6}$ Robert W. Binkley suggested in a commentary on an earlier version of this note that Jesus was in fact advancing only the modus tollens argument. The "Why do you not hear?" before the quoted passage and the explanation at the end would on this interpretation be mere rhetorical flourishes. Jesus would indeed give the explanation, but would not infer it. This is a possible alternative reading. If the reading I suggest attributes to Jesus an invalid argument, Binkley's reading would be preferable, or at least it would be unfair to charge Jesus with having argued invalidly.

7 William Hughes and others suggested in discussion that one could construe Jesus' initial statement, "He who is from God hears the words of God", as a biconditional. But, while "if" sentences often function as biconditionals, e.g. through the mechanism of conversational implicature identified by Grice (1989), a biconditional reading is not so natural with the form 
of words Jesus uses. And, on my interpretation, the biconditional reading is unnecessary to rescue Jesus from the charge of arguing invalidly.

But it must be conceded that Jesus at least suggests in the context that whoever is not from God does not hear the words of God: he tells his hearers (8:44) that they are from the devil, which is apparently the alternative to being from God; he says $(8: 44)$ that there is no truth in the devil and that his hearers want to do what the devil wants; and he says (8:45) that his hearers do not believe him because he speaks the truth. Joe Novak pointed out to me that St. John's Gospel generally writes in terms of polar opposites treated as exhaustive: light versus dark, truth versus lies, God versus the devil, etc.

"Similar remarks can be made about John 15:18-19, where Jesus says, "If you were of the world, the world would love its own; but because you are not of the world, but I chose you out of the world; therefore the world hates you." Mark Vorobej has drawn to my attention that a contemporary logic text (Churchill 1990:19,573) analyzes this passage as an argument with the conclusion, "The world hates you." If so, then Jesus in effect commits the fallacy of denying the antecedent: he would be arguing from the premisses that you are not of this world and that, if you are of the world, the world loves you to the conclusion that the world does not love you. But, as in John 8:47, both the "because" (Greek "hoti") and the "therefore" (Greek "dia touto") are explanatory: Jesus is saying that the explanation of the world's hating his disciples is that they are not of the world. (The claim that the world hates his disciples is already implicit in Jesus' preceding remark (at John 15:18), "If the world hates you, know that it hated me before you," as well as in his subsequent remark (at John 15:20), "As they persecuted me, they will persecute you.") As in John 8:47, the preceding sentence functions as a premiss supporting this explanation. Jesus' argument is therefore as follows:

Premiss: If you were of the world, the world would love its own [i.e. you],

Conclusion: The world hates you because you are not of the world but I picked you out of the world.

And this argument has the same valid form of reasoning from a sufficient causal condition (here expressed in ungeneralized form) to an explanation of the absence of that of which it is a sufficient causal condition by the absence of the sufficient condition.

${ }^{9}$ Some logicians, including (so I am told) Peter Geach, have advised logicians and theorists of argument to stay away from scriptural examples. My advice would be less restrictive: to give scriptural examples thorough and detailed analysis before charging them with being fallacious. Likewise for such sophisticated texts as the writings of eminent philosophers.

\section{References}

Aland, Kurt, Black, Matthew, Metzger, Bruce M., and Wikgren, Allen (1966). The Greek New Testament. London: United Bible Societies.

Burke, Michael (1994). "Denying the Antecedent", Informal Logic 16: 23-30.

Churchill, Robert Paul (1990). Logic: An Introduction, 2nd edition. New York: St. Martin's Press.

George, Rolf (1983). "A Postscript on Fallacies", Journal of Philosophical Logic 12: 319-325.

Goodwin, William Watson, and Gulick, Charles Burton (1930). Greek Grammar. Boston: Ginn and Company.

Grice, H. P. (1989). Studies in the Way of Words. Cambridge, MA: Harvard. 
Robertson, A.T. (1919). A Grammar of the Greek New Testament in the Light of Historical Research. Third edition. New York: George H. Doran Company.

Whately, Richard (1827). Elements of Logic. Second edition. London: Mawman.

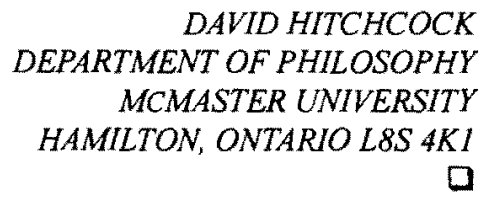

